\title{
Photochemical Properties of Precipitated Titania Aerosol Produced by Powdering of Crystal Rutile under Ambient Air
}

\author{
Valery Zakharenko ${ }^{1}$ and Alexey Filimonov ${ }^{2}$ \\ ${ }^{1}$ Laboratory of Solar Energy Transformation, Boreskov Institute of Catalysis, Novosibirsk 630090, Russia \\ ${ }^{2}$ Departments of Physical and Colloidal Chemistry, Tomsk State University, Tomsk 634050, Russia \\ Correspondence should be addressed to Valery Zakharenko; zakh@catalysis.ru
}

Received 21 June 2012; Revised 16 August 2012; Accepted 20 August 2012

Academic Editor: Ewa Schab-Balcerzak

Copyright (c) 2013 V. Zakharenko and A. Filimonov. This is an open access article distributed under the Creative Commons Attribution License, which permits unrestricted use, distribution, and reproduction in any medium, provided the original work is properly cited.

\begin{abstract}
It is shown that the quantum yields of oxygen photoadsorption and carbon dioxide photodesorption on $\mathrm{TiO}_{2}$ are significantly higher under illumination by quanta with energy from the surface absorption region of $\mathrm{TiO}_{2}$ when it is not produced by the traditional way, but from the rutile crystal. The magnitudes and spectral dependencies of the quantum yield of photoadsorption and photodesorption for $\mathrm{TiO}_{2}$ produced from a monocrystal are determined. A mechanism of a sharp increase of the titania photoadsorption activity in the surface absorption region is proposed.
\end{abstract}

\section{Introduction}

The Earth's atmosphere has a capacity for self-cleaning from various gaseous pollutants under photoinduced heterogeneous processes over aerosols particle surfaces. To determine the separation efficiency it is necessary to obtain quantitative data on efficiency of photoinduced processes under atmospheric conditions and to simulate conditions of aerosol particle creation in the troposphere.

The creation of troposphere aerosol particles with fine crystallised structure was the result of a dispersion of various lithosphere minerals over very long time [1]. Thus, aerosol particles are microcrystals with a sufficiently ideal crystalline structure as opposite to particles of the high-dispersion adsorbents (photoadsorbents) and catalysts (photocatalysts) produced by traditional way, that is, under conditions of preparation $\mathrm{TiO}_{2}$ with a high specific surface in laboratory and industry. The powder-like samples from minerals can be expected to have properties differing from those of the artificially produced compounds. In accordance with the published data, photocatalytic reactions over semiconductor metal oxides [2], as well as photosorption processes in oxide insulators [3], include a stage of transfer of electrons and holes formed under illumination to the surface. Consequently, the probability that free carriers will reach the surface and change the reactivity of surface atoms of the lattice or adsorbed atoms and molecules depends on the conditions of the carriers transfer in the bands (valence and conductivity bands). At small sizes of particles (highdispersion oxides insulators $\gamma-\mathrm{Al}_{2} \mathrm{O}_{3}$ and $\mathrm{SiO}_{2}$ with a specific surface of 150 and $300 \mathrm{~m}^{2} \cdot \mathrm{g}^{-1}$, resp.), these bands fail to be formed and the photosorption activity relative to halogen-containing organic compounds has not been observed [3].

A significant part of the tropospheric continental aerosol mainly consists of well-crystallised silicate and quartz microparticles. In this case, photosorption activity relative to halogen-containing organic compounds is observed. As data [4-6] show, efficient photoinduced processes actually proceed on particles of the coastal or desert sand with the participation of organic and halogen organic compounds. To simulate conditions for producing well-crystallised particles in tropospheric aerosol, the powder-like titanium dioxide was made through grinding a titania crystal in rutile modification 


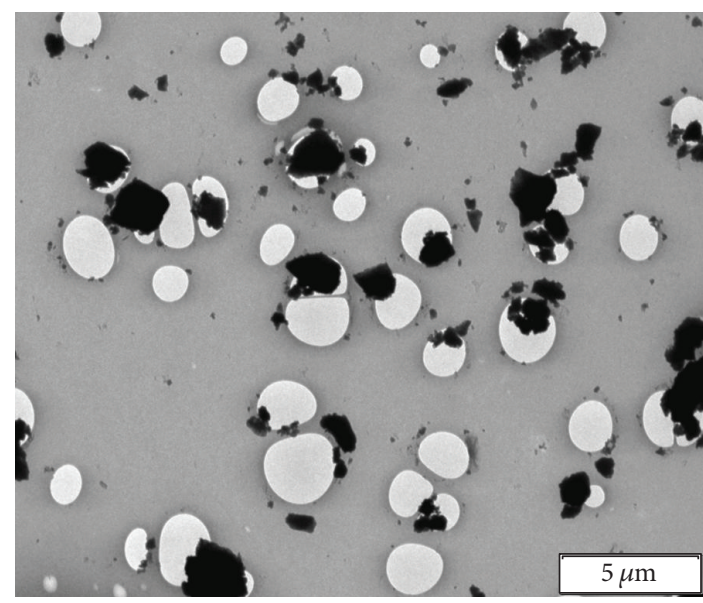

(a)

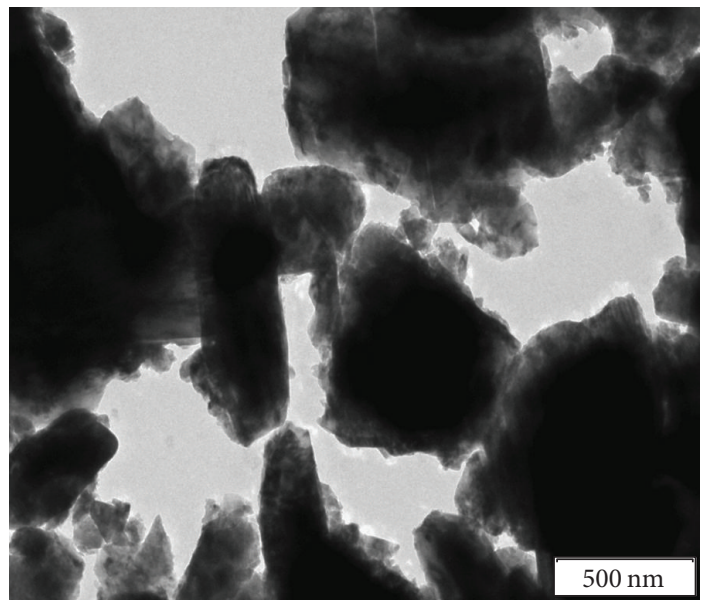

(c)

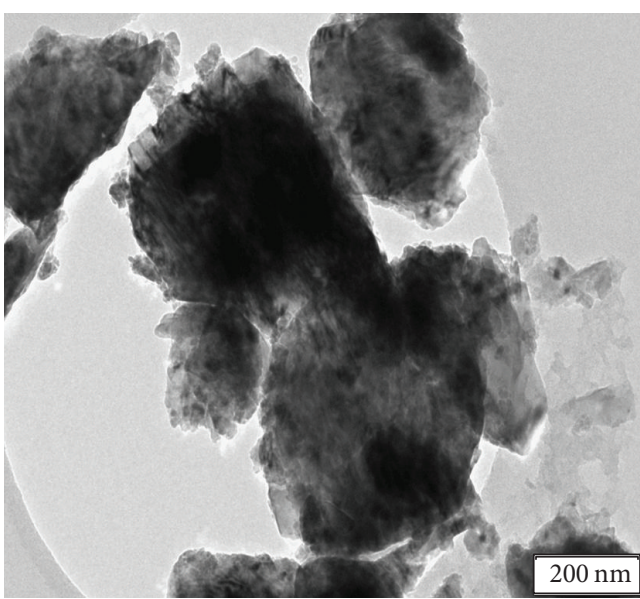

(b)

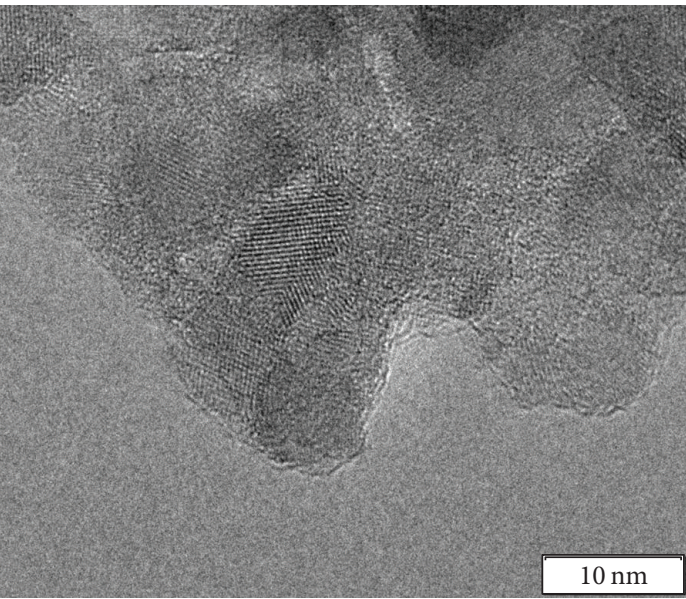

(d)

FIGURE 1: TEM picture of the titania powder produced by grinding of crystal rutile.

under ambient air. This paper is devoted to the photochemical properties of the titania dispersed powders obtained from a monocrystal.

\section{Experimental}

The titania crystal in rutile modification produced by the Czochralski method was broken and grinded in a corundum mortar. The specific surface of prepared powder was equal to $1.6 \mathrm{~m}^{2} \cdot \mathrm{g}^{-1}$.

The X-ray diffraction spectrum of the powder-like sample was recorded with an HZG-4C diffractometer using $\mathrm{CuK}_{\alpha^{-}}$ radiation. According to the results of the X-ray analysis, the titanium dioxide sample matched the titanium dioxide of the rutile crystalline structure.

The titania spectra were subjected to transmission electron microscopy (TEM) analysis on a JEOL model JEM-2010 instrument operated at acceleration at $200 \mathrm{~V}$ (Figure 1).

To expose the oxides under UV radiation, an OSL-1 illuminator with a high-pressure mercury lamp (DRSH-250, power $250 \mathrm{~W}$ ) including a thermal water filter and UV filter (transmission band between 270 and $390 \mathrm{~nm}$ ) was used. The total radiation flux density reaching the reactor's surface and recorded by an RTH-20C thermopile was equal to $\sim 1$ milliwatt $\cdot \mathrm{cm}^{-2}$ for this filter. To separate monochromatic radiation, interference filters were used.

The diffuse reflectance spectra of the powder-like titania were recorded with a SPECORD M-40 spectrophotometer under ambient air. In the studies a powder-like magnesium oxide was used as the reference standard.

The titanium dioxide as a water suspension was applied to the interior wall of the cylindrical quartz reactor and dried in air at room temperature for a week. After soldering to a high vacuum setup, the reactor with the sample was pumped out at room temperature for $20 \mathrm{~min}$. Later on the pumping out was performed through a trap with a cooling liquid (ethyl alcohol cooled to $173 \mathrm{~K}$ ) in order for water in the gas phase of the reactor volume and at the oxide surface to be present continuously. The prolonged evacuation of the reactor volume for 1 hour in high-vacuum installation through a trap resulted in partial removal of carbon dioxide. 


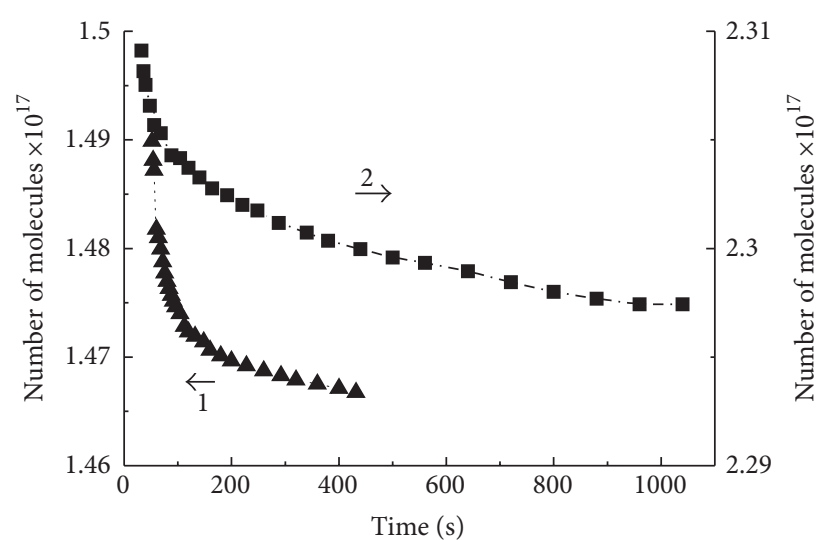

FIGURE 2: Kinetics of Freon 134a (1) and Freon 22 (2) adsorption on a powder-like sample produced from a $\mathrm{TiO}_{2}$ monocrystal.

As a result, quasi-equilibrium filling of the surface with $\mathrm{CO}_{2}$ was established.

The amount of $\mathrm{O}_{2}, \mathrm{~N}_{2} \mathrm{O}, \mathrm{NO}$, and $\mathrm{CO}_{2}$ molecules, halogen-containing organic compounds, and products of their interaction with the titania surface were determined using a Pirani gauge and mass spectrometer by sampling gas from the reaction volume through a dosing valve.

The quantum yield of the photoadsorption (photodesorption) was found as the ratio of the quantity of photoadsorbed (photodesorbed) molecules to the number of quanta passed through the reactor's frontal (transparent) wall.

\section{Results and Discussion}

After pumping out the reactor through the trap cooled down to $173 \mathrm{~K}$, mainly $\mathrm{NO}$ gas evolved from the titania surface (fourfold greater than $\mathrm{CO}_{2}$ accumulated inside the reactor). Our earlier measurements of the amount and composition of gases evolved from the oxide surfaces in the dark (with other metal oxides produced in laboratory or industrial conditions) were characterised mainly by $\mathrm{CO}_{2}$ desorption. Thus, the amount of carbon dioxide evolved from the $\mathrm{MgO}$ surface is equal approximately to $10 \%$ of the monolayer, and nitrogen oxides (predominantly $\mathrm{N}_{2} \mathrm{O}$ ) are equal approximately to $1 \%$ [7].

It can be supposed that nitrogen oxide (II) is produced in a sufficient amount when grinding the $\mathrm{TiO}_{2}$ crystal in air due to molecular nitrogen oxidation at centres formed at the break of the $\mathrm{Ti}-\mathrm{O}$ bonds of the titania lattice. The NO generation is also possible through the well-known reaction of $\mathrm{N}_{2} \mathrm{O}$ decomposition at the electron donor centre of the metal oxide surface $[8,9]$. In this case, $\mathrm{N}_{2} \mathrm{O}$ is adsorbed from air like the carbon dioxide.

The dark adsorption of Freon $134 \mathrm{a}\left(\mathrm{CF}_{3}-\mathrm{CH}_{2} \mathrm{~F}\right)$ or Freon $22\left(\mathrm{CHF}_{2} \mathrm{Cl}\right)$, insignificant in magnitude $(0.03 \%$ of the oxide surface monolayer at a pressure of $\sim 10^{-2}$ Torr inside the reactor volume), is observed for the powder-like titania produced from a crystal of the rutile crystalline modification. The adsorption kinetics of these gases are presented in Figure 2.

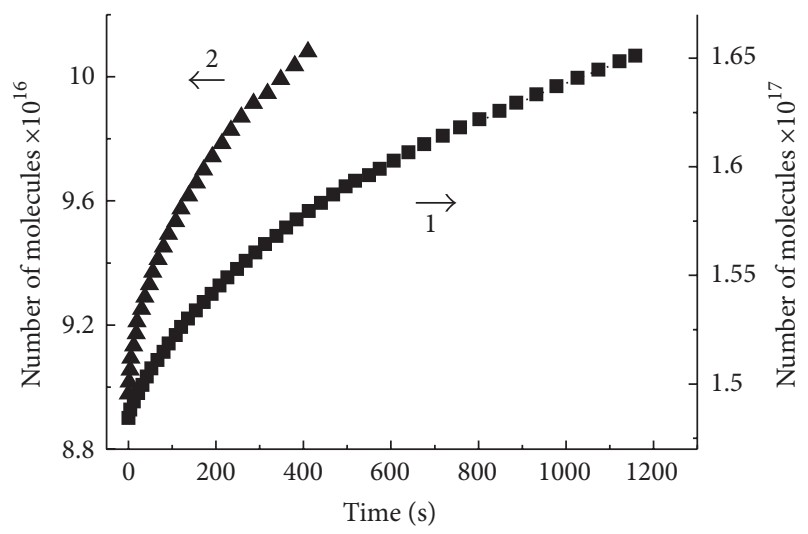

FIGURE 3: $\mathrm{CO}_{2}$ photodesorption kinetics in the presence of Freon 134a (1) and Freon 22 (2) on a powder-like sample produced from a $\mathrm{TiO}_{2}$ monocrystal.

3.1. Photodesorption. When illuminating the titania surface through a UV filter in the presence of Freon 134a or Freon 22 (after saturation of the dark adsorption of these gases [7, 8]), the carbon dioxide photodesorption is observed, while the photoadsorption of the Freons is low.

The transmission spectrum of the UV filter is given, for example, in [10]. The $\mathrm{CO}_{2}$ photodesorption kinetics in the presence of Freon 134a or Freon 22 is shown in Figure 3.

The kinetics of photodesorption is characterised by the fast desorption of carbon dioxide in the initial time of illumination (up to 3-5 min), followed by slow desorption with a constant rate. In the first case, probably, desorption is connected with classic $\mathrm{CO}_{2}$ photodesorption under illumination of the surface under quanta with energy from the fundamental absorption band of $\mathrm{TiO}_{2}$ [11]. In the second case, desorption is attributed to the photocatalytic reaction of the oxidation oxygen of an oxide of the by adsorbed carbon-containing compounds (e.g., carbon oxide from air) followed by reducing the titanium dioxide surface [12]. During this process, as it follows from mass spectrometric data, the magnitude of mass peak 44 increases by several times (Figure 4, curve 1). However, photocatalytic oxidation of the considered Freons by surface oxygen does not occur, because peaks 33 (Freon 134a) and 51 (Freon 22) do not decrease under illumination both through the UV filter and without a filter (Figure 4, curve 2).

The titanium dioxide is characterised by the absence of photocatalytic activity in the oxidation of methane, ethane, and their halogen derivatives like Freon $134 \mathrm{a}\left(\mathrm{CF}_{3}-\mathrm{CH}_{2} \mathrm{~F}\right)$ and Freon $22\left(\mathrm{CHF}_{2} \mathrm{Cl}\right)$ [13]. However, this activity of $\mathrm{TiO}_{2}$ relative to carbon oxide, unsaturated hydrocarbons, carbon acids, alcohols, and other organic compounds is very considerable [14].

Measurements of the $\mathrm{CO}_{2}$ photodesorption rate under illumination by monochromatic light at different wavelengths (via the use of interference Filters) and light flux intensities allowed to calculate quantum yield of the $\mathrm{CO}_{2}$ photodesorption. The calculation results are given in Figure 5 (curve 1). Curve 1 shows the diffusion reflection spectrum of 


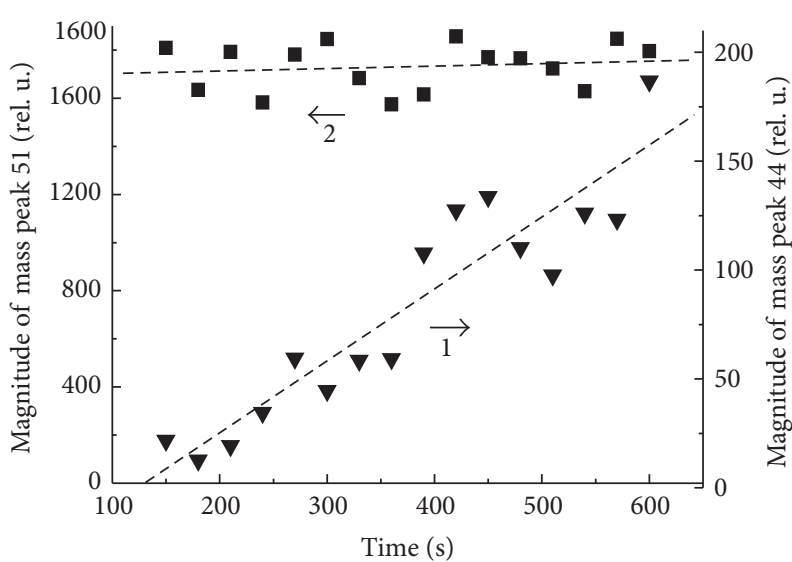

FIgURE 4: Kinetics of the variation of peaks 44 (1) and 51 (2) of masses in the mass spectra of $\mathrm{CO}_{2}$ and Freon 22, respectively, under illumination of the $\mathrm{TiO}_{2}$ surface through the UV filter in the presence of Freon.

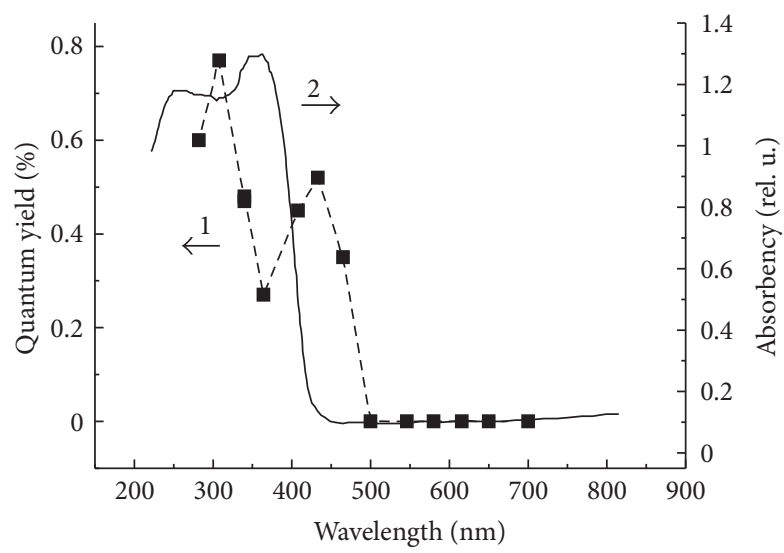

FIGURE 5: Spectral dependencies for the titanium dioxide sample produced from a monocrystal: (1) the quantum yield of $\mathrm{CO}_{2}$ photodesorption in the presence of Freon 134a and (2) the optical density relative to $\mathrm{MgO}$.

the powder-like $\mathrm{TiO}_{2}$ measured relative to magnesium oxide as the reference standard.

3.2. Photoadsorption. The photoadsorption activity of titania produced from a monocrystal of the rutile crystalline modification $\left(\mathrm{TiO}_{2}-\mathrm{I}\right)$ was compared with that of the titania sample produced from powder-like $\mathrm{TiO}_{2}$ of the anatase modification $\left(\mathrm{TiO}_{2}\right.$-II). The anatase was heated at $1273 \mathrm{~K}$ for two hours in air in order to obtain from the anatase phase (basically) the rutile phase (basically). Further, the surface of $\mathrm{TiO}_{2}$-II obtained in such a way was cleaned from the adsorbed layer by long-time, high-temperature, oxygen vacuum treatment. Manometric and mass spectrometric data have shown the absence of the dark adsorption of oxygen on $\mathrm{TiO}_{2}$-II, which probably is connected with the oxygen preadsorption during the sample cooling in oxygen. The dark adsorption was also absent for the $\mathrm{TiO}_{2}$-I sample, because the surface at its formation through grinding the crystal was saturated with

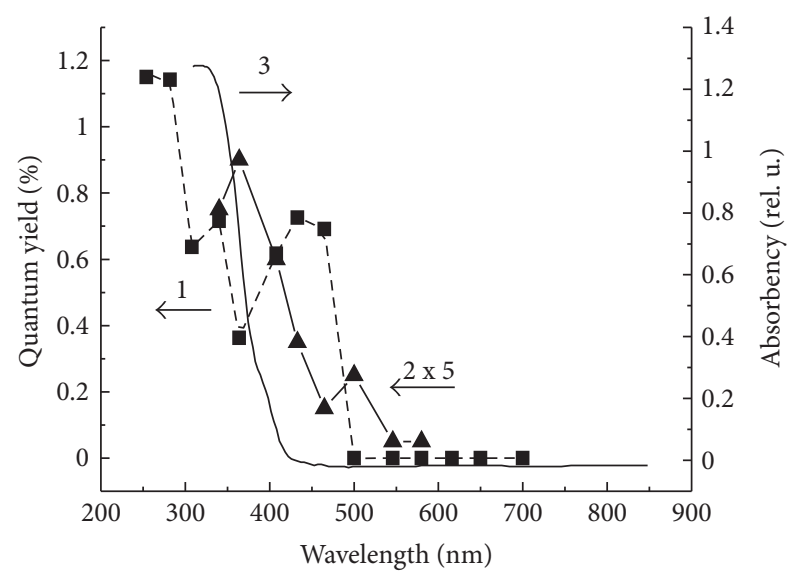

Figure 6: The spectral dependencies for titanium dioxide samples: the quantum yields of $\mathrm{O}_{2}$ photoadsorption at $\mathrm{TiO}_{2}-\mathrm{I}(1)$ and $\mathrm{TiO}_{2}-\mathrm{II}$ (2); the optical density of $\mathrm{TiO}_{2}$-II relative to $\mathrm{MgO}$ (3).

oxygen from air. Moreover, the surface reconstruction by means of high-temperature treatment in a vacuum or in some reducing atmosphere was not conducted in the experiment.

The spectral dependence of the quantum yield of oxygen photoadsorption for the $\mathrm{TiO}_{2}$-sample is presented in Figure 6 (curve 1). Of interest are high-photoadsorption quantum yields at $\lambda>400 \mathrm{~nm}$ (corresponding to the $\mathrm{TiO}_{2}$ surface absorption band), which are close in magnitude to quantum yields in the range of the $\mathrm{TiO}_{2}$ absorption. At a wavelength of about $465 \mathrm{~nm}$, the quantum yield is $0.7 \%$; at $\lambda=340 \mathrm{~nm}$, it is $0.75 \%$ (Figure 6 , curve 1 ). The spectral dependence of the photoadsorption quantum yield for the $\mathrm{TiO}_{2}$-II sample is shown by curve 2. Comparing, the diffusion reflection spectrum for $\mathrm{TiO}_{2}-\mathrm{II}$ is also given. The quantum yield at a wavelength of $465 \mathrm{~nm}$ is $0.03 \%$ and at $340 \mathrm{~nm}$ is $0.15 \%$ for this sample. Close quantum yields in the surface absorption band were observed also for titanium dioxide produced through the burning in air of a pyrotechnic mixture including titanium microparticles [15].

The absorption in the range of energies of quanta less than the $\mathrm{TiO}_{2}$ forbidden band can be related to electron transition from deep surface levels of the oxide to the conduction band [16]. At the same time, the oxygen photoadsorption proceeds on the electron localised in the surface trap of the semiconductor oxide $[9,17]$. Thus, it can be supposed that the sharp increase of the quantum yield in the range of $\mathrm{TiO}_{2}$ surface absorption relative to oxygen is connected with the increase of deep surface levels formed at a break of the Ti-O bonds when producing powder-like oxide from a monocrystal.

\section{Conclusion}

It is discovered that in the band of solar tropospheric radiation $(\lambda>300 \mathrm{~nm})$, the photochemical activity of titanium dioxide produced through grinding the monocrystal under ambient air is significantly higher than that of the compound 
produced by traditionally way, that is, $\mathrm{TiO}_{2}$ prepared with a high specific surface.

It can be expected that the photochemical properties of other oxides produced from minerals ( $\mathrm{MgO}$ from periclase, $\mathrm{SiO}_{2}$ from quartz, $\mathrm{Al}_{2} \mathrm{O}_{3}$ from corundum, etc.) will significantly differ from the properties of compounds produced in laboratory or industrial conditions. The formation of oxide particles from mineral crystals under natural conditions is accompanied by the formation of photochemically active solid tropospheric aerosol.

\section{References}

[1] I. Kostov, Mineralogy, Oliver and Boyd, London, UK, 1968.

[2] V. S. Zakharenko, "Photoinduced heterogeneous processes on phase chemical components of solid tropospheric aerosols," Topics in Catalysis, vol. 35, no. 3-4, pp. 231-236, 2005.

[3] V. N. Parmon and V. S. Zakharenko, "Photocatalysis and photosorption in the Earth's atmosphere," CatTech, vol. 5, no. 2, pp. 96-115, 2001.

[4] P. Ausloos, R. E. Rebbert, and L. J. Glasgov, "Photodecomposition of chloromethane adsorbed on silica surfaces," The Journal of Research of the National Institute of Standards, vol. 82, no. 1, pp. 1-8, 1977.

[5] V. A. Isidorov, E. M. Klokova, and I. V. Zgonnik, "About photostimulated decomposition halogen-containing organic components of the atmosphere at the surface of solid particles," Bulletin of Leningrad State University, no. 4, pp. 71-80.

[6] H. Wise and K. M. Sancier, "Photocatalyzed oxidation of crude oil residue by beach sand," Catalysis Letters, vol. 11, no. 3-6, pp. 277-284, 1991.

[7] V. S. Zakharenko and V. N. Parmon, "On the composition of adsorbed layer of the magnesium oxide surface under impact of the air atmosphere," Russian Journal of Physical Chemistry, vol. 73, no. 1, pp. 124-129, 1999.

[8] A. A. Lisachenko and F. I. Vilesov, "Photocatalytic properties of oxides in the region of nonintrinsic absorption," Advances in Photonics, no. 4, pp. 18-34, 1974.

[9] A. M. Volodin, "EPR investigation of the mechanism of formation of centres at the $\mathrm{MgO}$ surface in the presence of $\mathrm{N}_{2} \mathrm{O}$ and $\mathrm{O}_{2}$ molecules," Russian Journal of Physical Chemistry, vol. 11, no. 8, pp. 1054-1063, 1992.

[10] V. S. Zakharenko A and N. Moseichuk, "Adsorption of freons by calcium carbonate under atmospheric conditions," Journal of Atmospheric and Oceanic Optics, vol. 18, no. 5-6, pp. 506-510, 2005.

[11] N. Van Hieu and D. Lichtman, "Bandgap radiation induced photodesorption from titanium oxide surfaces," Surface Science, vol. 103, no. 2-3, pp. 535-541, 1981.

[12] V. S. Zakharenko and V. N. Parmon, "Spectral Dependences of Simultaneous Photogenerated Evolution of $\mathrm{H}_{2}$ and $\mathrm{CO}_{2}$ from a $\mathrm{Pt} / \mathrm{TiO}_{2}$ Suspension in a $1 \mathrm{~N} \mathrm{H}_{2} \mathrm{SO}_{4}$ Solution," Kinetics and Catalysis, vol. 37, no. 3, pp. 427-430, 1996.

[13] M. R. Hoffmann, S. T. Martin, W. Choi, and D. W. Bahnemann, "Environmental applications of semiconductor photocatalysis," Chemical Reviews, vol. 95, no. 1, pp. 69-96, 1995.

[14] X. Chen and S. S. Mao, "Titanium dioxide nanomaterials: synthesis, properties, modifications and applications," Chemical Reviews, vol. 107, no. 7, pp. 2891-2959, 2007.

[15] V.S. Zakharenko and S. A. Khromova, "On applicability of solid aerosol produced by burning in air of titanium microparticles to liquidation of consequences of technogenic catastrophes," Russian Journal of Ecology, vol. 15, no. 4, pp. 226-234, 2006.

[16] V. S. Vavilov, Effect of Radiation on Semiconductors, Moscow, Russia, 1963.

[17] A. R. González-Elipe and J. Soria, "Electron spin resonance study of the radicals formed by ultraviolet irradiation of $\mathrm{TiO}_{2}$ in the presence of sulphur dioxide and oxygen," Journal of the Chemical Society, Faraday Transactions, vol. 82, no. 3, pp. 739-745, 1986. 

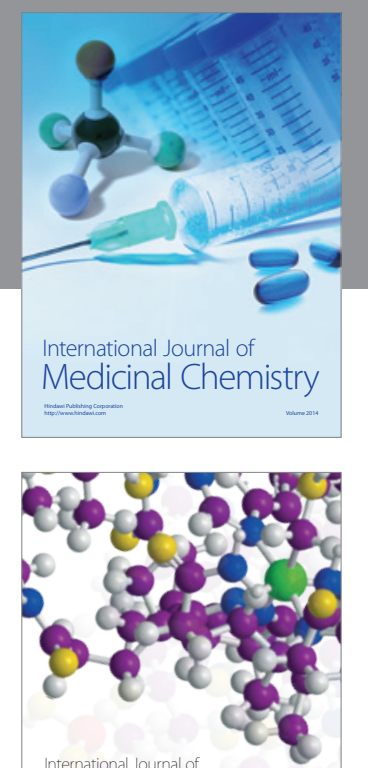

\section{Carbohydrate} Chemistry

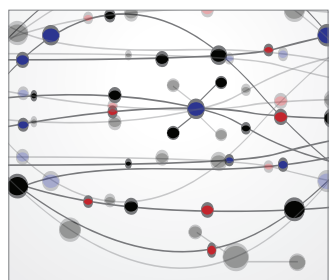

The Scientific World Journal
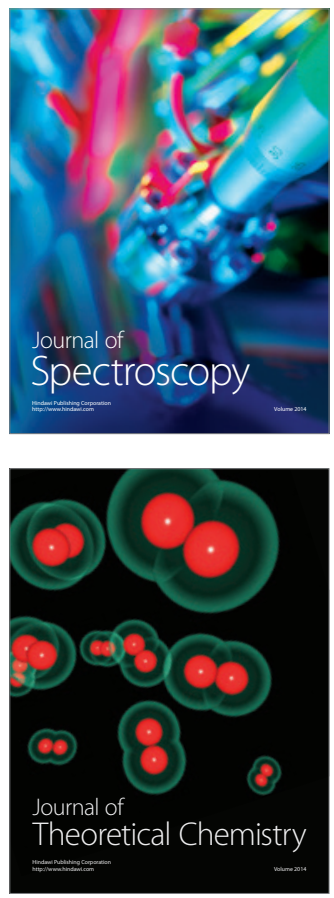
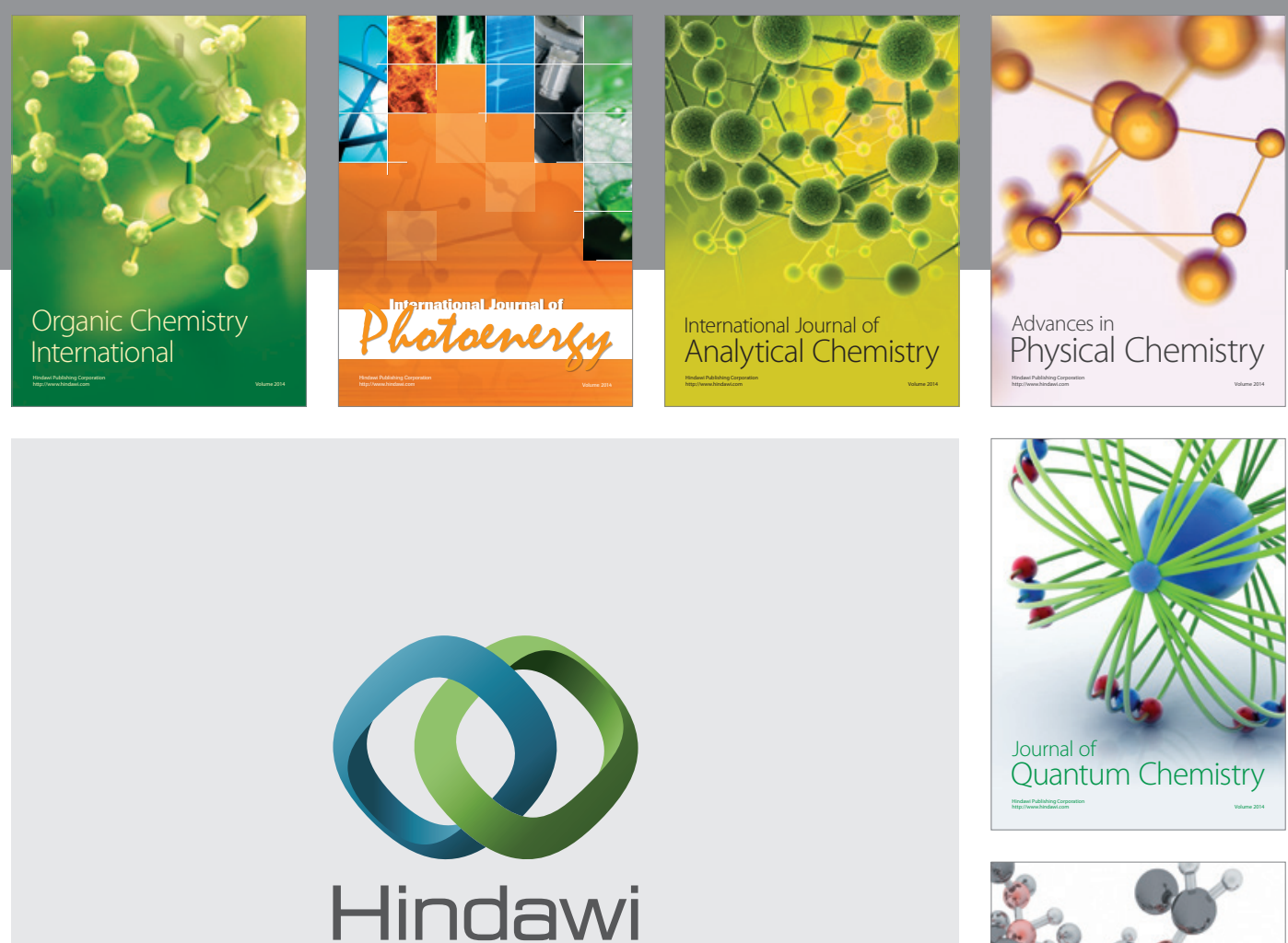

Submit your manuscripts at

http://www.hindawi.com

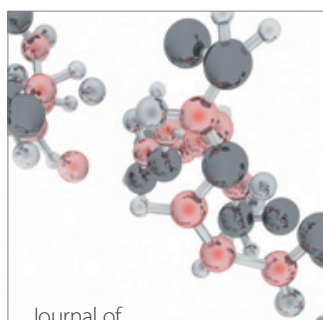

Analytical Methods

in Chemistry

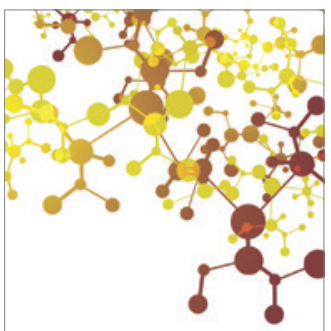

Journal of

Applied Chemistry

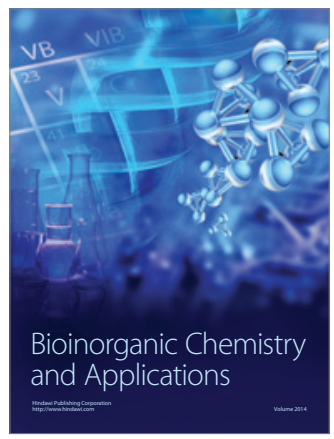

Inorganic Chemistry
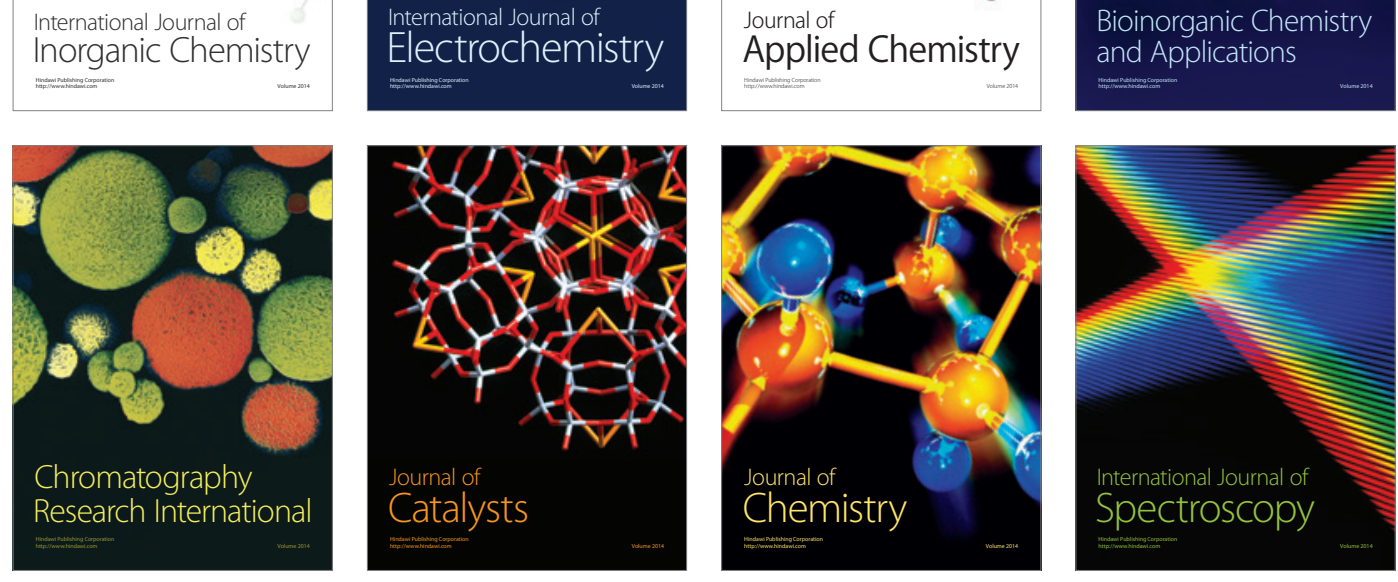